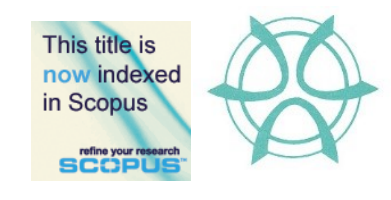

\title{
ASSESSING CHILDREN'S CONNECTEDNESS TO NATURE THROUGH THEIR INTEREST IN NATURAL ELEMENTS
}

\author{
Nor Diyana Mustapa ${ }^{1}$, Nor Zarifah Maliki ${ }^{2}$, Nor Fadzila Aziz ${ }^{3}$ \& Aswati \\ Hamzah $^{4}$ \\ ${ }^{I}$ Faculty of Architecture and Ekistics \\ UNIVERSITI MALAYSIA KELANTAN \\ ${ }^{2}$ School of Housing, Building and Planning \\ UNIVERSITI SAINS MALAYSIA \\ ${ }^{3}$ School of Educational Studies \\ UNIVERSITI SAINS MALAYSIA
}

\begin{abstract}
This study aims to assess children's connectedness to nature (CTN) through drawing based on their preferences and interest in natural elements in spaces. A sequential explanatory mixed-method research design was employed to achieve the aim. For the quantitative part, questionnaires were distributed to 760 children in 20 schools located in Kedah and Penang, Malaysia. For the qualitative part, 72 children were grouped into draw and focus groups. The children in the qualitative part were chosen from low-, moderate- and high-level CTN groups. The results confirm that children's CTN can be assessed through their drawing based on their interest in natural elements in spaces. The findings indicated that children from the high-level CTN group had more interest in natural elements in spaces compared to the children in the moderate- and low-level of CTN groups.
\end{abstract}

Keywords: children, connectedness to nature, drawing, natural elements

\footnotetext{
${ }^{1}$ Lecturer at Universiti Malaysia Kelantan. Email: diyana.m@umk.edu.my
} 
Nor Diyana Mustapa, Nor Zarifah Maliki, Nor Fadzila Aziz \& Aswati Hamzah

Assessing Children's Connectedness to Nature Through Their Interest in Natural Elements

\section{INTRODUCTION}

Connectedness to nature (CTN), which develops from childhood, is important because its effects endure to adulthood. Studies have found that the adults who frequently visit green areas (Thompson, Aspinall, \& Montarzino, 2007) and adults who have positive perceptions of the natural environment and natural recreation activities (Jorgensen \& Anthopoulou, 2007) are those who have strong CTN that stems from their childhood. A strong CTN developed since childhood has also been found to influence environmental career choices and environmental concerns (Chawla, 2007) and their attitude towards activities with nature (Lohr $\&$ Pearson-mims, 2005) when they become adults. Although the development of $\mathrm{CTN}$ is a lifelong process and could change over time, researchers have suggested that childhood, especially middle childhood age, is important because it is a critical period for the development of CTN (Kellert, 2005). Hence, the importance of CTN during childhood and its crucial role in the assessment and measurement of children's CTN at an early age should not be ignored.

Researchers have developed various instruments to measure children's CTN. However, the instruments are mostly quantitative instruments. Despite the importance of the quantitative instrument in generalizing the results and identifying the position of children's CTN along a continuum, many researchers have suggested that the qualitative approach is the best method to use with children. The qualitative approach best suits and offers a more reliable approach to understanding children's thoughts, feelings and experiences (Chawla, 2006b). With focus on children and nature, several studies have used drawing to evaluate children's perceptions and attitudes towards nature and the environment and found it to be a useful method for understanding children's relationship with nature and the environment (Labintah \& Shinozaki, 2014). Drawing helps stimulate children to give a response and to communicate (Horstman, Aldiss, Richardson, \& Gibson, 2008). However, limited studies have used drawing to assess children's CTN.

Previous studies have demonstrated that children are fascinated with the natural environment (Korpela, Kyttä, \& Hartig, 2002; Mahidin \& Maulan, 2012), specifically, areas with trees, flowers and grass (Loukaitou-sideris, 2003). A study with adults showed that adults with higher CTN plant more trees in their gardens (Lin et al., 2017). Similarly, studies with children found that children with high CTN have more interest in natural areas (Ballantyne \& Packer, 2002) and also natural elements especially the elements that they are familiar (Bizerril, 2004; Jansson, Gunnarsson, Mårtensson, \& Andersson, 2014). Interest in natural elements in spaces is one of the constructs or indicators to assess children's CTN. Hence, this study aims to assess children's CTN using drawing based on their interest in natural elements in spaces. 


\section{METHODOLOGY \\ Research Design}

Mixed method research design, specifically sequential explanatory, was employed to achieve the aims of this study. The sequential explanatory mixedmethod research design involves data collection and analysis of the quantitative data in the first stage, followed by qualitative data collection and analysis in the second stage. In the first stage, questionnaires were used to identify the children's CTN levels. Three groups, namely, low-, moderate- and high-level of CTN, were formed based on the quantitative results. The differences between the groups regarding their preferences toward natural elements in spaces were explored through drawing. Data collection was conducted from April 2016 to June 2017.

\section{Participants}

This study involved children aged 10 and 11 years old from 20 urban and rural schools in Kedah and Penang, Malaysia. Middle childhood children were chosen as the respondents because children of this age explore the outdoor environment extensively and they learn more from their environment (Mårtensson et al., 2014). The sample for the quantitative part was chosen based on stratified random sampling. Overall, the total sample size is 760 , with 383 children from Kedah and 378 children from Penang.

Meanwhile, in the qualitative stage, the participants were selected based on purposive sampling, specifically, intensity sampling. The 72 children chosen for the quantitative part consists of 24 children from the low-, moderate- and high-level CTN groups. In total, 12 groups of three to four children per group were created. Before data collection, approval was obtained from the Ministry of Education, Malaysia and the Department of Education from both states and respective schools. Verbal assent was also obtained from the children by asking whether they wanted to volunteer to participate in this study.

\section{Procedure}

In the first phase, the children were asked to answer the CTN scale with guidance from the researcher and assistant researchers. A pilot study was conducted before the actual data collection to ensure that the children understood the items on the survey and to test the reliability of the CTN instrument. In the actual data collection, copies of the questionnaire were distributed personally to the children in the selected classes in each school. The researcher read the questions and statements out loud one by one and explained each one to the children and had a better understanding of each statement. The children took about 30 to 40 minutes to complete the questionnaire.

In the second phase, the qualitative part, the selected children that comprise the low-, moderate- and high-level CTN groups were asked to draw their dream home on an A4 paper to explore their CTN through their interest in 
Nor Diyana Mustapa, Nor Zarifah Maliki, Nor Fadzila Aziz \& Aswati Hamzah

Assessing Children's Connectedness to Nature Through Their Interest in Natural Elements

natural elements in spaces. The instruction was "Imagine that in the future, you own a house with a big yard. What do you want to have in the yard? Draw your dream home". The children were given about 30 minutes to draw. The children's CTN level was determined from the elements they included in their future dream home yard. Their drawing also reflected their experiences with nature, knowledge of nature, familiarity with nature, and their preferences towards natural elements. Then, the children were asked to share what they drew during the focus group discussion. The discussions were recorded using a voice recorder.

\section{Research Instrument}

In the quantitative stage, the questionnaire was used to measure the children's CTN level. The questionnaire distributed to the children was in the Malay language. The questionnaire for this study has two sections, namely, the children's background and CTN scale. The CTN scale consists of six constructs adapted from previous instruments. The constructs are nature awareness, environmental identity, enjoyment in nature, empathy towards nature, interest in nature activities, and interest in natural spaces. The CTN was measured by asking the children to indicate their level of agreement using a smiley icon (Abebe \& Ennew, 2009) on each item for each construct in a four-point Likert scale. In the qualitative stage, drawing was used to identify children's preferences towards natural elements in spaces.

\section{Data Analysis}

The quantitative data were analysed using IBM SPSS Statistics Version 22. Descriptive analysis of the mean and standard deviation was used to identify the children's CTN level. Descriptive analysis was also used to analyse the children's background. Then, content analysis was used to examine the discussion with the children on their drawing. Content analysis was conducted for the focus and drawing groups and the results were cross-checked. Finally, summative content analysis was conducted by computing the recurring codes, sub-themes and themes for CTN to explore further the differences between children from low-, moderate-, and high-level CTN groups.

\section{RESULTS}

\section{Level of Children's Connectedness to Nature}

Descriptive analysis was performed to identify the children's CTN level. All three groups (low, moderate and high level) are of unequal sizes. The mean for each group is calculated using Mean $\pm 1 \mathrm{SD}(\mathrm{M}=3.31$ and $\mathrm{SD}=0.34)$.

The means for each group are as follows: low $(\mathrm{M}<=2.97)$, moderate $(2.97<\mathrm{M}<3.65)$ and high $(\mathrm{M}>=3.65)$. The frequency and percentage of children for each group are as shown in Table 1. More than two thirds $(66.8 \%)$ of the children had a moderate level of CTN, $16.7 \%$ of the children had a high level of 
CTN and $16.4 \%$ of the children had a low level of CTN. The result shows most of the children have a moderate level of CTN. Then, 24 children were chosen randomly from each group for the qualitative part, which involved the drawing and sharing parts.

Table 1: Percentage for Low, Moderate, and High Level of CTN

\begin{tabular}{llll}
\hline CTN level & & Frequency & Percentage \\
\hline Low level & $(\mathrm{M}<=2.97)$ & 125 & $16.4 \%$ \\
\hline Moderate level & $(2.97<\mathrm{M}<3.65)$ & 508 & $66.8 \%$ \\
\hline High level & $(\mathrm{M}>=3.65)$ & 127 & $16.7 \%$ \\
\hline
\end{tabular}

\section{Themes from Drawing}

The results from drawing show that most of the children had an interest in having natural elements in their dream home with $70.8 \%, 87.5 \%$ and $91.7 \%$ respectively for the low-, moderate- and high-level CTN groups. Based on the content analysis from 72 children, the elements that were drawn and mentioned by the children were categorised into five themes, namely, plants, scenery, animals, hardscape, and relaxation. Other than those mentioned themes, some children also included clouds and the sun in their drawing. However, those elements were included in the analysis because the focus is on the natural elements in their future dream home. Table 2 shows the number and percentage of children that drew for each theme. The results from Table 2 show that the most natural element that the children included in their drawing is plants with $93.1 \%$, followed by hardscape, animals, scenery and relaxation. A huge difference was observed between the low-, moderate- and high-level groups for scenery and animal themes.

Table 2: Number and Percentage of Children for Interest in Natural Elements Subthemes

\begin{tabular}{|c|c|c|c|c|c|}
\hline \multirow{2}{*}{$\begin{array}{l}\text { Group } \\
(\mathrm{n}=24 \text { per } \\
\text { group) }\end{array}$} & \multicolumn{5}{|c|}{ Themes } \\
\hline & Plants & Scenery & Animals & Hardscape & Relaxation \\
\hline Low & 21 & 2 & 9 & 6 & 1 \\
\hline Moderate & 23 & 7 & 4 & 16 & 2 \\
\hline High & 23 & 15 & 15 & 16 & 1 \\
\hline $\begin{array}{l}\text { Total } \\
(n=72)\end{array}$ & $\begin{array}{c}67 \\
93.1 \%\end{array}$ & $\begin{array}{c}24 \\
33.3 \%\end{array}$ & $\begin{array}{c}28 \\
38.9 \%\end{array}$ & $\begin{array}{c}38 \\
52.8 \%\end{array}$ & $\begin{array}{c}4 \\
5.6 \%\end{array}$ \\
\hline
\end{tabular}

\section{Plants}

Limited difference was observed between children from the low-, moderate- and high-level group for the plant themes because most of the children included plants in their home yard. The children drew trees, ornamental plants, fruit plants, vegetables, and grass in their home yard. A 10-year-old boy from urban Penang (high-level) explained his drawing as follows: 'I want to have roses, orchids, 
Nor Diyana Mustapa, Nor Zarifah Maliki, Nor Fadzila Aziz \& Aswati Hamzah

Assessing Children's Connectedness to Nature Through Their Interest in Natural Elements

vegetables and rambutan trees in my future house yard' (see Figure 1). Some of the children included a vegetable patch for cultivation purposes. For example, a 10 -year-old girl from urban Penang (high- level) described her dream house as ' $I$ want my dream house to be located on a hill...the air is fresh. I want to have a swimming pool, river, small bridge, a vegetable patch and chickens. I want to save money' (see Figure 2), while an 11-year-old girl from rural Penang (moderate-level) explained, 'My dream house has a garden with flowers, vegetables and a fishpond. There is also a swimming pool ... At the top of my house, I also have a garden full of plants' (see Figure 3). Even though children from all three groups have included plants in their drawing, a difference can be observed between these three groups when the children from the high-level and moderate-level groups drew plants for cultivation purposes.

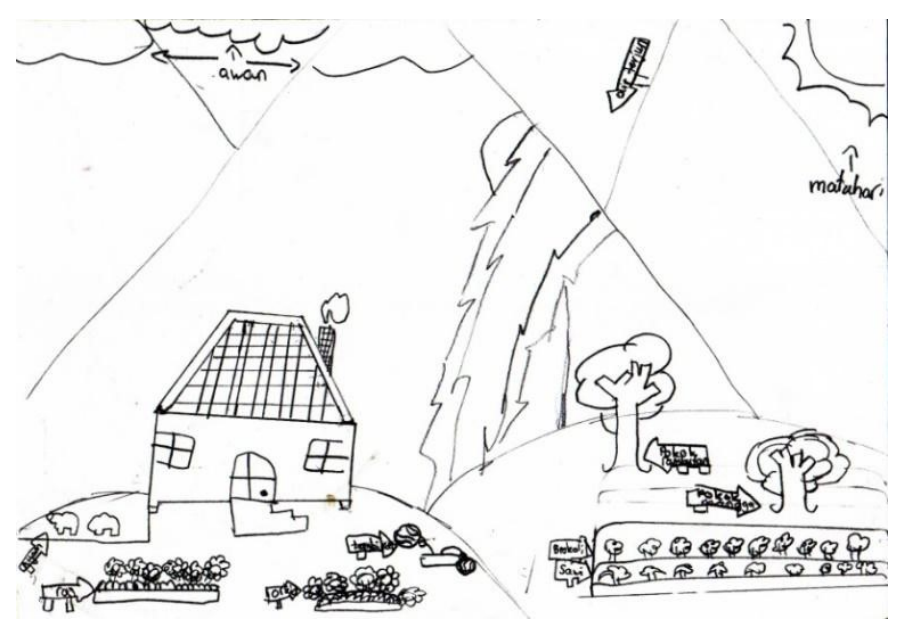

Figure 1: Drawing by a 10-year-old Boy from Urban Penang with High Level of CTN. 
PLANNING MALAYSIA

Journal of the Malaysia Institute of Planners (2020)



Figure 2: Drawing by a 10-year-old Girl from Urban Penang with High Level of CTN.



Figure 3: Drawing by an 11-year-old Girl from Rural Penang with Moderate level of CTN.

\section{Hardscape}

The second most mentioned and drawn element by the children is hardscape at $52.8 \%$. Children from the high-level group had many ideas compared to children from the moderate- and low-level groups. Instead of drawing a fishpond and a swimming pool, children in the high-level group also drew other elements such as wakaf, henhouse, butterfly house and treehouse. For example, an 11-year-old girl from rural Kedah (high-level) drew a fishpond, butterfly house and 
Nor Diyana Mustapa, Nor Zarifah Maliki, Nor Fadzila Aziz \& Aswati Hamzah

Assessing Children's Connectedness to Nature Through Their Interest in Natural Elements

swimming pool. She shared that 'My dream house has a fishpond, tortoise, butterfly house, swimming pool and garden' (see Figure 4).

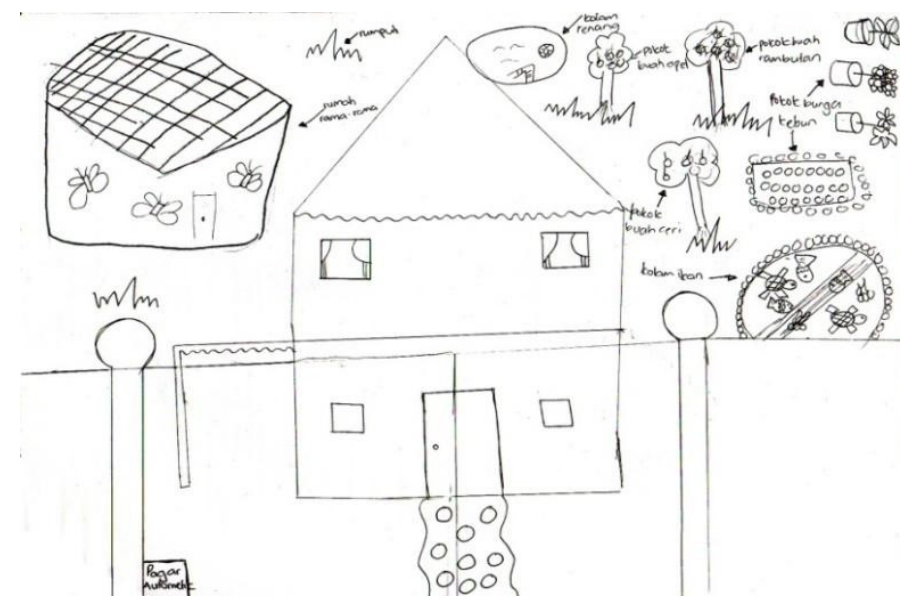

Figure 4: Drawing by an 11-year-old Girl from Rural Kedah with High Level of CTN

Scenery

Regarding scenery, $33.3 \%$ of the children drew scenery, such as paddy fields, rivers, hills, mountains, waterfalls and beaches. Table 2 indicating a decreasing trend from the high-level group to the low-level group. More children in the highlevel group included the scenery and landforms in their drawing, followed by children from the moderate- and low-level groups. A 10-year-old boy from urban Penang (high-level) explained what he had drawn when he shared, 'I want to live near the hills, mountains, waterfalls, and rivers' (see Figure 1). An 11-year-old boy from urban Penang (moderate-level) described his drawing, stating that ' $I$ want to live near the beach because I like the sound of the waves and I want to have coconut trees. I can hear birds chirping and I can always drink coconut water' (see Figure 5). A 10-year-old girl from urban Penang (low-level) explained, "I want to live near a river and a hill". Some other children explained they wanted to have a view of natural scenery because of the beauty and the fresh air. For instance, a 10-year-old boy from urban Penang (high level) had drawn a hill near his dream house. He explained, 'My dream house will have a hill view... The hill is beautiful' (see Figure 1). 


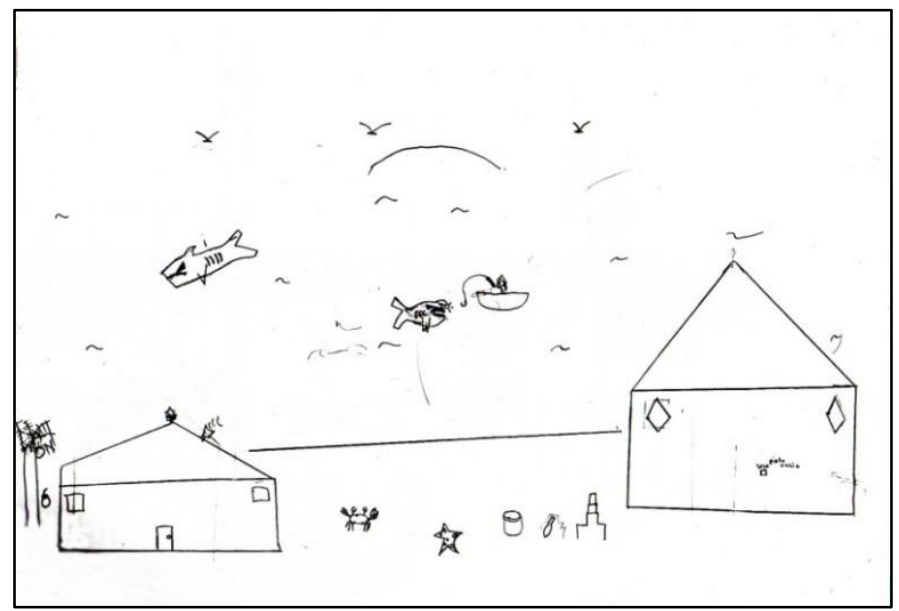

Figure 5: Drawing by an 11-year-old Boy from Urban Penang with Moderate Level of CTN

\begin{abstract}
Animals
As to the animal theme, $38.9 \%$ of the children included animals in their drawing. Most of the animals that the children drew were domestic animals, such as cats, chickens, ducks, tortoise, insects, fish, and birds. For instance, a boy aged 10 from rural Penang (high level) described his drawing by stating that, 'I want to keep rabbits and birds in my house yard'. Another 10-year-old boy, from rural Kedah (high- level), explained, 'I want to have a cat and chicken in my future house'. Figures 2 and 3 shows the children wanted to have chickens in their future dream house yard.

\section{Relaxation}

Some of the children $(5.6 \%)$ also included elements of the relaxation such as theme park, playground, and jogging track in their drawing. For example, an 11year-old boy from urban Penang (moderate-level) had drawn a park and a jogging track. He further described, 'My dream house is shaped like a mushroom, has mango trees, grass, and a park with a jogging track' (see Figure 6). A 10-yearold girl, also from urban Penang (moderate level), had drawn a playground. She explained, 'I want my house to be in a tree and to have a playground' (see Figure 8). Interestingly, the children had also drawn different forms of house. The boy had drawn a house in a mushroom shape, whereas the girl had drawn a treehouse (see Figure 6).
\end{abstract}



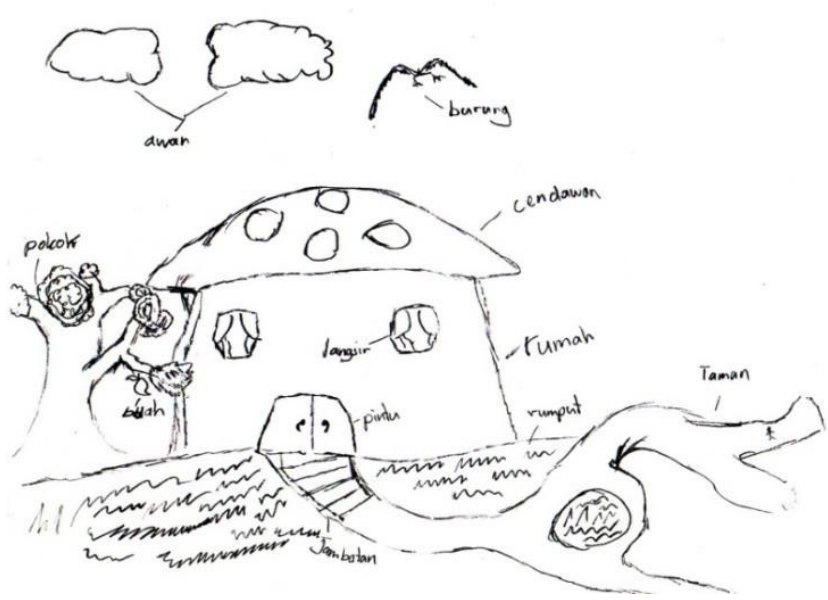

Figure 6: Drawing by an 11-year-old Boy from Urban Penang with Moderate Level of CTN.

\section{DISCUSSION}

Findings showed that children's CTN can be assessed through their interest in natural elements. The findings indicated that children from the high-level CTN group had more interest in natural elements in spaces compared to children in the moderate- and low-level CTN groups. Children in the high-level CTN group showed a greater appreciation towards nature because they included nature in a wider context other than plants. This finding supports findings in previous studies that children with higher CTN have more interest in natural areas (Lin et al., 2017, Ballantyne \& Packer, 2002). For example, most of them included natural landscapes as the background of their dream house. They described that they wanted to live nearby paddy fields, hills and waterfalls and they wanted to have a view of scenery every day. This statement further suggests that the children with high levels of CTN had more imagination compared to the children in the moderate- and low-level CTN groups. This finding may be related with the children's level of knowledge because children from the high-level CTN group demonstrated more knowledge about nature compared to children from the lowlevel CTN group, who demonstrated limited knowledge and therefore, lacked interest in natural spaces and elements.

The findings also show that children prefer familiar natural elements. The children mostly drew the natural elements that could be found in their own homes and based on what they had experienced. This result agrees with previous studies that found frequent direct experiences with natural elements to develop their interest in those elements (Bizerril, 2004; Jansson, Gunnarsson, Mårtensson, $\&$ Andersson, 2014). Hence, it is important to reconnect children with nature in 
the outdoor environment, as nowadays, the frequency of children having direct experiences with nature is declining. Another interesting finding is that some of the children drew plants used for cultivation purposes. These findings suggest children's knowledge is also reflected in their drawings. In addition, the children exhibited an appreciation of nature because of their enjoyment of being in nature and for aesthetic reasons.

Most importantly, the findings are in agreement with previous studies that drawing is an effective way of stimulating children to communicate and exhibit children's CTN (Labintah \& Shinozaki, 2014). Hence, drawing can become a toolkit to assess children's CTN in schools. The advantages of using drawing as part of the focus group activities are it helps stimulate children to give a response and to communicate because some children might have difficulties expressing their feelings and perceptions through verbal interviews. Although drawing is an enjoyable and easy way to gather information from children, the drawing method also has certain disadvantages. Some children felt inferior and were anxious about drawing because it was an activity that they felt they did not do well. In addition, given the limited time, some children were not able to draw as many elements as they had thought about because in the follow-up discussion, they explained that there were elements that they wanted to include but did not have time to draw. Despite these disadvantages, the drawing method helped the researcher to hold an interactive focus group discussion and explore children's CTN through their interest in natural elements.

\section{CONCLUSION}

Overall, this finding suggests that children's CTN can be assessed through their interest in natural elements using drawing. Hence, drawing can be a toolkit to measure children's CTN as part of an environmental programme or green module in schools. It is important to assess children's CTN at their early age as misconceptions of and misinformation on nature are difficult to correct later in adulthood. Moreover, CTN has a long-lasting effect until the children become adults. Future research can develop a rubric for the drawing activity to assess children's CTN.

\section{ACKNOWLEDGEMENTS}

The author would like to thank the Fundamental Research Grant Scheme (FRGS) (203/PPBGN/6711403) under the Ministry of Education (MOE) for funding this research. Also, thanks to University Sains Malaysia (USM) and University Malaysia Kelantan (UMK) for the continuous support. 
Nor Diyana Mustapa, Nor Zarifah Maliki, Nor Fadzila Aziz \& Aswati Hamzah

Assessing Children's Connectedness to Nature Through Their Interest in Natural Elements

\section{REFERENCES}

Abebe, T., \& Ennew, J. (2009). The right to be properly researched: How to do rightsbased, scientific research with children. Bangkok: Black on White Publications.

Ballantyne, R., \& Packer, J. (2002). Nature-based excursions: School students' perceptions of learning in natural environments. International Research in Geographical and Environmental Education, 11(3), 218-236.

Bizerril, M. X. A. (2004). Children's perceptions of Brazilian Cerrado landscapes and biodiversity. The Journal of Environmental Education, 35(4), 47-58.

Chawla, L. (2006). Research methods to investigate significant life experiences: Review and recommendations. Environmental Education Research, 12(3), 359-374.

Chawla, L. (2007). Childhood experiences associated with care for the natural world: A theoretical framework for empirical results. Children, Youth and Environments, 17(4), 144-170.

Jansson, M., Gunnarsson, A., Mårtensson, F., \& Andersson, S. (2014). Children's perspectives on vegetation establishment: Implications for school ground greening. Urban Forestry \& Urban Greening, 13(1), 166-174.

Jorgensen, A., \& Anthopoulou, A. (2007). Enjoyment and fear in urban woodlands - Does age make a difference? Urban Forestry and Urban Greening, 6(4), 267-278.

Kellert, S. R. (2005). Nature and childhood development. In Building for Life: Designing and Understanding the Human-Nature Connection (pp. 63-89). Washington, DC: Island Press.

Korpela, K., Kyttä, M., \& Hartig, T. (2002). Restorative experience, self-regulation, and children's place preferences. Journal of Environmental Psychology, 22(4), 387398

Labintah, S., \& Shinozaki, M. (2014). Children drawing: Interpreting school-group student's learning and preferences in environmental education program at TanjungPiai National Park, Johor Malaysia. Procedia - Social and Behavioral Sciences, 116, 3765-3770.

Lin, B. B., Gaston, K. J., Fuller, R. A., Wu, D., Bush, R., \& Shanahan, D. F. (2017). How green is your garden?: Urban form and socio-demographic factors influence yard vegetation, visitation, and ecosystem service benefits. Landscape and Urban Planning, 157, 239-246.

Lohr, V. I., \& Pearson-mims, C. H. (2005). Children's active and passive interactions with plants inflence their attitudes and actions towards trees and gardening as adults. HorTechnology, 15(3), 472-476.

Loukaitou-sideris, A. (2003). Children's common grounds: A study of intergroup relations among children in public settings. Journal of the American Planning Association, 69(2), 130-143.

Mahidin, A. M. M., \& Maulan, S. (2012). Understanding children preferences of natural environment as a start for environmental sustainability. Procedia - Social and Behavioral Sciences, 38, 324-333.

Thompson, C. W., Aspinall, P., \& Montarzino, A. (2007). The childhood factor: Adult visits to green places and the significance of childhood experience. Environment and Behavior, 40(1), 111-143.

Received: January 2020. Accepted: $15^{\text {th }}$ May 2020 